\title{
Prenatal Methamphetamine Exposure Induces Long-Lasting Alterations in Memory and Development of NMDA Receptors in the Hippocampus
}

\author{
R. ŠLAMBEROVÁ ${ }^{1}$, M. VRAJOVÁ ${ }^{2}$, B. SCHUTOVÁ ${ }^{1}$, M. MERTLOVÁ ${ }^{2}$, E. MACÚCHOVÁ ${ }^{1}$, \\ K. NOHEJLOVÁ ${ }^{1}$, L. HRUBÁ ${ }^{1}$, J. PUSKARČÍKOVÁ ${ }^{2}$, V. BUBENÍKOVÁ-VALEŠOVÁ ${ }^{2}$, \\ A. YAMAMOTOVÁ ${ }^{1}$
}

${ }^{1}$ Department of Normal, Pathological and Clinical Physiology, Third Faculty of Medicine, Charles University in Prague, Prague, Czech Republic, ${ }^{2}$ Department of Biochemistry and Brain Pathophysiology, Prague Psychiatric Center, Prague, Czech Republic

Received March 14, 2014

Accepted July 28, 2014

\begin{abstract}
Summary
Since close relationship was shown between drug addiction and memory formation, the aim of the present study was to investigate the effects of interaction between prenatal methamphetamine (MA) exposure and MA treatment in adulthood on spatial and non-spatial memory and on the structure of the N-methyl-D-aspartate (NMDA) receptors in the hippocampus. Adult male rats prenatally exposed to MA $(5 \mathrm{mg} / \mathrm{kg})$ or saline were tested in adulthood. Non-spatial memory was examined in the Object Recognition Test (ORT) and spatial memory in the Object Location Test (OLT) and in the Memory Retention Test (MRT) conducted in the Morris Water Maze (MWM), respectively. Based on the type of the memory test animals were injected either acutely (ORT, OLT) or long-term (MWM) with MA (1 mg/kg). After each testing, animals were sacrificed and brains were removed. The hippocampus was then examined in Western Blot analysis for occurrence of different NMDA receptors' subtypes. Our results demonstrated that prenatal MA exposure affects the development of the NMDA receptors in the hippocampus that might correspond with improvement of spatial memory tested in adulthood in the MWM. On the other hand, the effect of prenatal MA exposure on nonspatial memory examined in the ORT was the opposite. In addition, we showed that the effect of MA administration in adulthood on NMDA receptors is influenced by prenatal MA exposure, which seems to correlate with the spatial memory examined in the OLT.
\end{abstract}

\section{Key words}

Methamphetamine • Memory • Hippocampus • NMDA receptors • $\mathrm{NR} 1 \bullet \mathrm{NR} 2 \mathrm{~A} \bullet \mathrm{NR} 2 \mathrm{~B} \bullet \mathrm{PSD}-95$

\section{Corresponding author}

R. Šlamberová, Department of Normal, Pathological and Clinical Physiology, Third Faculty of Medicine, Ke Karlovu 4, 12000 Prague 2, Czech Republic. Fax: +420 224902750. E-mail: rslamber@lf3.cuni.cz

\section{Introduction}

Methamphetamine (MA) is a psychostimulant drug the abuse of which has become a serious problem during recent years (Griffiths et al. 2008, Hanson et al. 2004). Moreover, it is one of the most common drugs abused by pregnant women addicted to drugs (Marwick 2000). Since MA was shown to cross both, placental and hematoencephalic barrier easily (Dattel 1990, Nordahl et al. 2003), prenatal exposure to MA can result in developmental anomalies of the central nervous system (CNS) of exposed fetuses (Hrubá et al. 2009, Cho et al. 1991, Martin et al. 1976). In human studies, decreased volumes of hippocampus correlating with poorer performance on delayed verbal memory task were found in children prenatally exposed to MA (Chang et al. 2004). Impairment of cognitive functions caused by prenatal MA exposure was shown also in study demonstrating lower scores in visual recognition memory task in infants of MA abusing mothers (Struthers and Hansen 1992).

Interestingly, close relationship was shown between drug addiction and memory formation, such that brain engages similar molecular and cellular mechanisms 
to form addiction related memories as it does to form normal memories (Berke and Hyman 2000). As a result, prenatal MA exposure could affect the sensitivity to drugs when an individual encounters them again in adulthood, due to its effects on systems underlying memory formation. In our previous studies (BubeníkováValešová et al. 2009, Schutová et al. 2010) we showed that prenatal exposure to MA is able to change the responsiveness to acute MA dose in adulthood. However, rather than one single dose of $\mathrm{MA}$, long-term administration of MA is more expectable in young people experimenting with drugs of abuse (Griffiths et al. 2008). In addition, there may be differences between the effect of MA treatment (prenatal or adult) on spatial memory that is mostly associated with the hippocampus, and nonspatial memory in which the hippocampus does not seem to play a crucial role. Therefore, the first aim of the present study was to investigate the effects of interaction between prenatal MA exposure and acute or long-term MA treatment in adulthood on the spatial and non-spatial memory in adult male rats.

Since N-methyl-D-aspartate (NMDA) receptors are known for their essential role in mediating memory and learning consolidation in the hippocampus (Davis et al. 1992), protein analysis of NMDA receptors subunits in rats' hippocampi was performed. Multiple subunits of NMDA receptors were identified depending on their localization in the brain. Functional NMDA receptors require the presence of the NR1 subunits in addition to variable combinations of the NR2 subunits (Lynch et al. 1994). In the adult hippocampus, predominantly NR2A and NR2B subunits appear (Ishii et al. 1993, Le Greves et al. 2006). While NR2B is strongly expressed at birth, the NR2A subunit increases from second postnatal week and replaces the NR2B subunits (Laurie et al. 1997). This seems to be connected with increased synaptic plasticity (Constantine-Paton and Cline 1998).

In addition to the subunits, postsynaptic density protein 95 (PSD-95) seems to be central in organizing the NMDA receptor signaling complex. This protein was shown to regulate long-term potentiation (LTP) - a process necessary for memory formation (Sheng 2001, Schnell et al. 2002). Thus, the second objective of the present study was to investigate the impact of prenatal MA exposure and long-term MA challenge in adulthood on the levels of NR1, NR2A, NR2B and PSD-95 in the hippocampi of adult male rats.

To sum up, the aim of the present study was to investigate the effect of prenatal MA exposure and adult
MA treatment (acute or chronic) on spatial and nonspatial memory and on expression of the NMDA receptor subunits in the hippocampus of adult male rats.

\section{Methods}

The procedures for animal experimentation utilized in this study were reviewed and approved by the Institutional Animal Care and Use Committee and are in agreement with the Czech Government Requirements under the Policy of Humans Care of Laboratory Animals (No. 246/1992) and with subsequent regulations of the Ministry of Agriculture of the Czech Republic.

\section{Animals and housing}

Adult male (300-400 g) and female (250-300 g) Albino Wistar rats from Charles River Laboratories International, Inc. were purchased in ANLAB (Prague, the Czech Republic), bred and fertilized as described in Šlamberová et al. (2005). The day of the delivery was counted as postnatal day (PD) 0 .

A total of 24 litters were used in the experiment. The number of pups in each litter was adjusted to 12 . Whenever possible, the same number of male and female pups was kept in each litter. To avoid litter bias, pups were cross-fostered on PD 1, so that one mother usually raised 6 pups of her own and 6 pups from mother with different treatment (see below). Two animals (each with different prenatal exposure) from each litter were used to avoid litter bias. The rest of the animals were used in other studies. On PD 21, animals were weaned and housed in groups, separated by sex and left undisturbed under standard conditions until adulthood.

\section{Drug administration}

For Prenatal exposure, the pregnant dams were divided into two groups: MA group and saline (SAL) group. The females from MA group were administered D-methamphetamine $\mathrm{HCl}$ (Sigma-Aldrich ${ }^{\circledR}$ ) at a dose of $5 \mathrm{mg} / \mathrm{kg}$ and volume of $1 \mathrm{ml} / \mathrm{kg}$ subcutaneously (s.c.) through the entire gestation period (i.e. from the first to the last day of gestation) (Šlamberová et al. 2005). This MA dose was chosen because it results in similar fetal brain drug concentrations to those found in human infants of MA abusing women (Acuff-Smith et al. 1996). This is also a standard dose used in our experiments (Šlamberová et al. 2005). The females from SAL group were administered $0.9 \% \mathrm{NaCl}$ solution s.c. at the same time and volume as MA. On PD 1, the offspring were marked 
according to the prenatal exposure by using the intradermal application of black India ink; offspring of MA mothers in the left foot pad, offspring of SAL mothers in the right foot pad.

In adulthood, prenatally exposed males (both MA and SAL) were administered s.c. either with MA $(1 \mathrm{mg} / \mathrm{kg})$ or SAL $(1 \mathrm{ml} / \mathrm{kg})$. In adulthood the animals were treated with lower dose than prenatally, because the lower dose is usually used in studies testing responsiveness to repeated drug exposure (Crozatier et al. 2003, Glatt et al. 2000) and because this dose does not induce stereotypy behavior that might affect the test performance (Schutová et al. 2013, Šlamberová et al. 2011).

To summarize, rats were divided into four experimental groups (Prenatal exposure/Adult treatment): SAL/SAL; SAL/MA; MA/SAL; MA/MA. Different groups of animals $(n=8-12)$ were tested in two types of memory tests (non-spatial and spatial (O'Keefe 1999)). Non-spatial memory was examined in the Object Recognition Test (ORT) and spatial memory in the Object Location Test (OLT) and in the Memory Retention Test (MRT) conducted in the Morris Water Maze (MWM), respectively. Based on the type of the memory test animals were injected either acutely (ORT, OLT) or chronically (MWM) as described below. After each testing, animals were sacrificed and brains were removed. The hippocampus was then examined in Western Blot analysis for occurrence of different NMDA receptors' subtypes.

Evaluation of memory after acute MA treatment in adulthood

\section{Object Recognition Test}

The ORT measures the exploration of novel versus familiar objects, which is a component of recognition memory and concentration (Ennaceur et al. 1997). The test consists of three parts: habituation, training and testing. Animals ( $\mathrm{n}=10-12$, PD 60-90) were habituated to the empty square opaque arena (70x70x60cm) for three days, each day for $20 \mathrm{~min}$. On the fourth day the animal was trained by placing the rat into the arena for $5 \mathrm{~min}$ to explore two identical objects placed in the arena (plastic cylinder). After $5 \mathrm{~min}$ the rat was returned into the home-cage. The testing box and the objects were then cleaned to eliminate odors by $70 \%$ alcohol. In the testing phase, animals were injected with single dose of MA $(1 \mathrm{mg} / \mathrm{kg})$ or SAL $(1 \mathrm{ml} / \mathrm{kg}) 30 \mathrm{~min}$ prior to placing to the box with one of the original object and one new object of similar size (pot turned upside down) on the same places. In 1 min after exercise the rat was placed again into the arena for a period of $5 \mathrm{~min}$ to explore both objects (one new object and one familiar object). The following elements of behavior were considered as the exploration of the subject: sniffing to the object, close circumvention of the object with the sniffing or observation, rearing to the object, with or without sniffing. Calculation of the interest in a new object in the testing phase, which is called the Investigation Ratio (IR) was calculated as the ratio between the time spent by exploration of a new object $\left(\mathrm{T}_{\text {new }}\right)$ to the total time spent by exploration of both objects $\left(\mathrm{T}_{\text {total }}\right)\left(\mathrm{IR}=\mathrm{T}_{\text {new }} / \mathrm{T}_{\text {total }}\right)($ Ennaceur et al. 1997$)$.

\section{Object Location Test}

Another group of adult male rats $(n=10-12, P D$ 60-90) was examined in the OLT. The OLT follows on the same rules as the ORT and it consists of the same three parts (habituation, training, testing). The difference is that OLT measures the exploration time of two same objects but one is in a novel location. It assesses especially spatial memory and discrimination. In the testing phase, animals were injected with single dose of MA (1 mg/kg) or SAL (1 ml/kg) 30 min prior to placing to the box with objects, one in the original location and one in the new location, the time spent by explorations were measured. The IR, calculation of the interest in an object placed in a new location in the testing phase, was calculated as the ratio between the time spent by exploration of the object in a new place $\left(\mathrm{T}_{\text {new }}\right)$ to the total time spent by exploration of both objects $\left(\mathrm{T}_{\text {total }}\right)(\mathrm{IR}=$ $\left.\mathrm{T}_{\text {new }} / \mathrm{T}_{\text {total }}\right)$ (Ennaceur et al. 1997).

\section{Evaluation of memory after long-term MA treatment in adulthood}

\section{Memory Retention Test in Morris Water Maze}

The male offspring ( $\mathrm{n}=12$, PD 60-90) were tested for spatial memory in the MWM. The MRT was performed on the $12^{\text {th }}$ day of the experiment after 6 days of training (learning procedure) followed by 5 days of a break. MA ( $1 \mathrm{mg} / \mathrm{ml} / \mathrm{kg} /$ day) or saline $(1 \mathrm{ml} / \mathrm{kg} /$ day $)$ was administered during the entire time of the experiment (11 days). During the learning period MA was administered always after the training session, thus it would affect the memory formation process, but not the swimming performance of the animal ffor detailed 
explanation see our spatial learning study of Schutová et al. (2009)\}.

Within the spatial memory test animals were supposed to find the hidden platform within $60 \mathrm{~s}$ as they were trained during the learning sessions. The platform was located $1 \mathrm{~cm}$ under the water line at the same position as during the learning test. Each animal was subjected to 8 trials. The trials were tracked using a video-tracking system EthoVision XT7 (Noldus Information Technology, Netherlands). The following parameters were analyzed: latency of platform acquisition $[\mathrm{s}]$, distance traveled $[\mathrm{cm}]$, search error $[\mathrm{cm}]$, and the velocity of swimming $[\mathrm{cm} / \mathrm{s}]$.

In addition, search strategies (swimming pathways) of individual animal were manually analyzed after track acquisition on the day of spatial memory testing. Note that strategies of swimming are being considered as important sign of animal's ability to show the spatial learning and not just a random searching for the platform (Janus 2004). The following search strategies were assigned as in our previous spatial learning study (Schutová et al. 2009): (1) Thigmotaxis (wall-hugging) - a persistent swim along the wall of the pool that could include sporadic swims towards the center of the pool, (2) Random search - swimming over the entire area of the pool in straight swims or in wide circular swims, (3) Scanning - swimming over the central area of the pool, (4) Chaining - circular swimming at a fixed distance from the wall, in which the platform was located, (5) Focal search in an incorrect quadrant - direct swim to an incorrect quadrant of the pool followed by loops and turns there, (6) Focal search in the target quadrant - direct swim to the correct quadrant of the pool followed by loops and turns there, (7) Spatial search - a direct swim path to the platform.

\section{Western Blotting}

Rats were decapitated immediately after the memory testing. The brains were rapidly removed, placed on ice and the hippocampi were dissected and stored at $-70{ }^{\circ} \mathrm{C}$ until Western blot analysis.

Dissected hippocampi were homogenized in $1.0 \mathrm{ml}$ of lysis buffer ( $320 \mathrm{mM}$ sucrose; $10 \mathrm{mM}$ Tris, pH 7.4; 0.2 mM EDTA; $2 \mathrm{mM}$ PMSF; $1 \mathrm{mM}$ 2-mercaptoethanol and a cocktail of protease inhibitors, Sigma, Germany). Crude synaptosomal (P2) fractions were isolated from hippocampal homogenates and resuspended in a loading buffer $(63 \mathrm{mM}$ Tris; $10 \%$ glycerol; $2 \%$ SDS; $5 \%$ 2-mercaptoethanol and $0.01 \%$ bromophenol blue). The protein concentration was determined by the Bradford method using bovine serum albumin (BSA) as a standard (Bio-Rad, USA). The re-suspended material was used for the electrophoresis in the $7.5 \%$ polyacrylamide gel (Criterion Cell, Bio-Rad, USA) followed by electroblotting in the Criterion blotter (Bio-Rad, USA). Nonspecific binding was blocked with $3 \%$ BSA or $5 \%$ non-fat dry milk dissolved in PBS-T buffer. Blots were incubated overnight with antiNMDAR1 as primary antibody (1:1000; Millipore, USA), anti-PSD-95 (1:500, SantaCruz, USA), and $2 \mathrm{~h}$ with antiNR2A and anti-NR2B (1:500; Millipore, USA) and the loading control with an anti- $\alpha$-tubulin antibody $(1: 1000$; Exbio, CZ) for $1 \mathrm{~h}$. Then, the blots were washed in PBS$\mathrm{T}$ buffer and incubated for $1 \mathrm{~h}$ with a horseradish peroxidase-conjugated secondary antibody (1:3000; Dako, Denmark). Detections were performed with a chemiluminescent substrate (Pierce, USA) and evaluated by the Gel Doc Analysis system (Bio-Rad, USA).

\section{Statistical methods}

As there were no differences in the animals of the same prenatal exposure that were raised by mothers of different drug treatment, the raising mother (biological vs. foster) was not taken as a factor for statistical analyses.
A

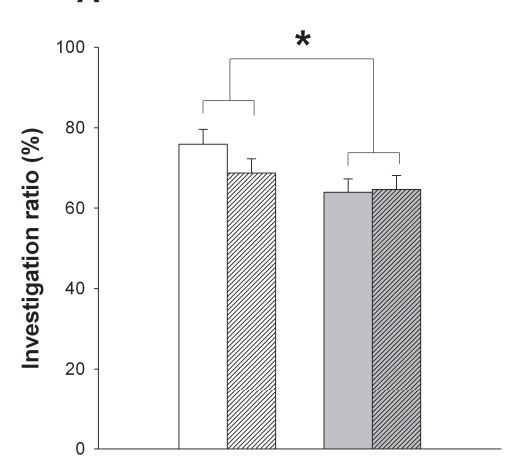

B

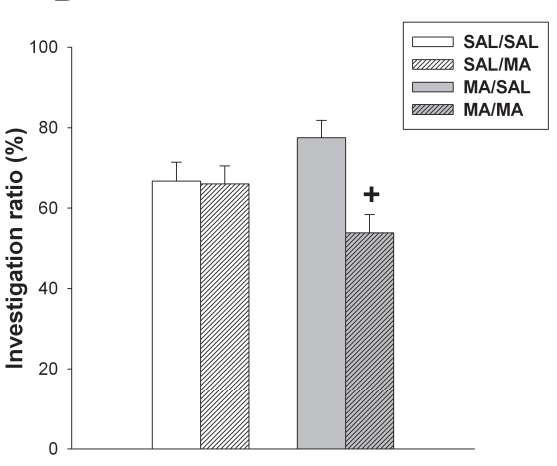

Fig. 1. Memory after acute MA treatment in adulthood. The effect of prenatal MA exposure and acute MA treatment in adulthood tested in the Object Recognition Test (A) and the Object Location Test (B). Values are mean \pm SEM $(n=8-12)$. $* \mathrm{p}<0.05=$ main effect of Prenatal exposure; prenatal saline $>$ prenatal $M A$, $+p<0.01=M A / M A<M A / S A L$ 
In the ORT and OLT tests, a Two-way ANOVA (Prenatal exposure $x$ Adult treatment) was used. In the MRT examined in the MWM, a Two-way ANOVA (Prenatal exposure $x$ Adult treatment) with Repeated measure (Trials) was applied. $\mathrm{Chi}^{2}$ test was used to analyze the frequency of the search strategies. In the Western Blot analysis, a Two-way ANOVA (Prenatal exposure $x$ Adult treatment) was used. Moreover, because the ratio of NR2A and NR2B receptor subunits have been
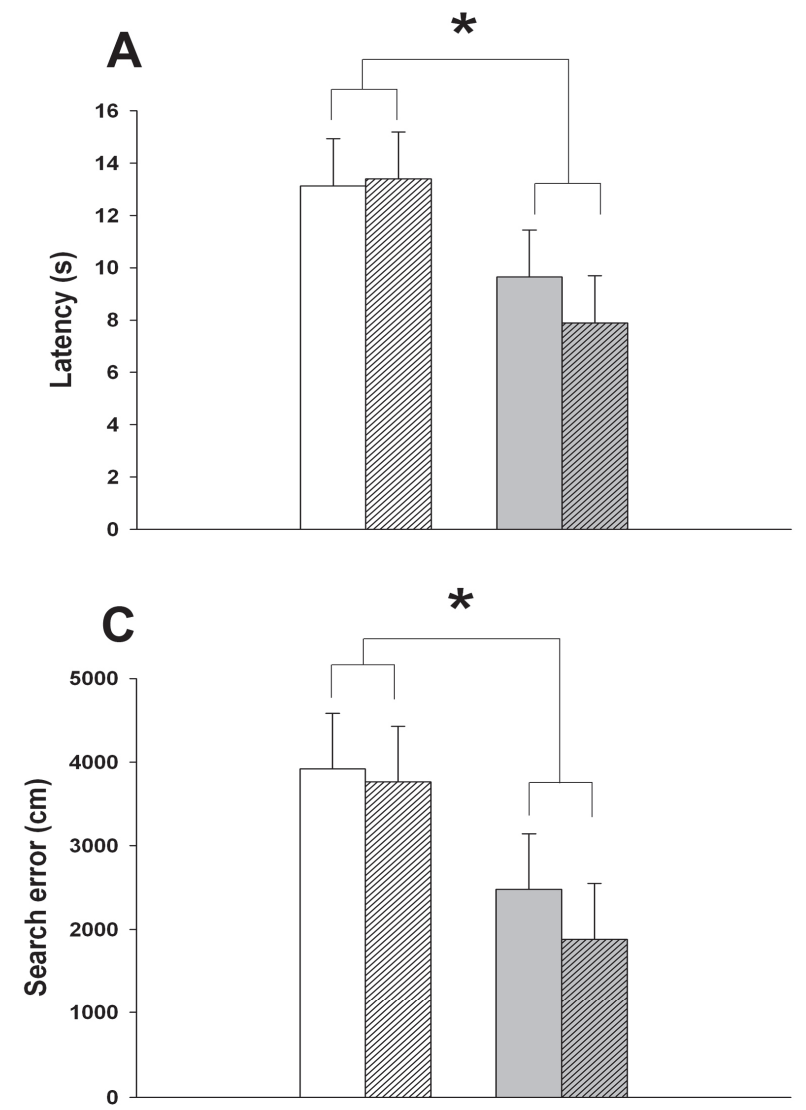

shown to be important for synaptic plasticity and cognition (Constantine-Paton and Cline 1998, Loftis and Janowsky 2003) an additional Three-way ANOVA (Prenatal exposure $x$ Adult treatment $x$ NR2 subunit) was conducted to analyze differences in NR2A and NR2B occurrence in all groups. Bonferroni test was used for post-hoc comparisons. Differences were always considered significant if $\mathrm{p}<0.05$.
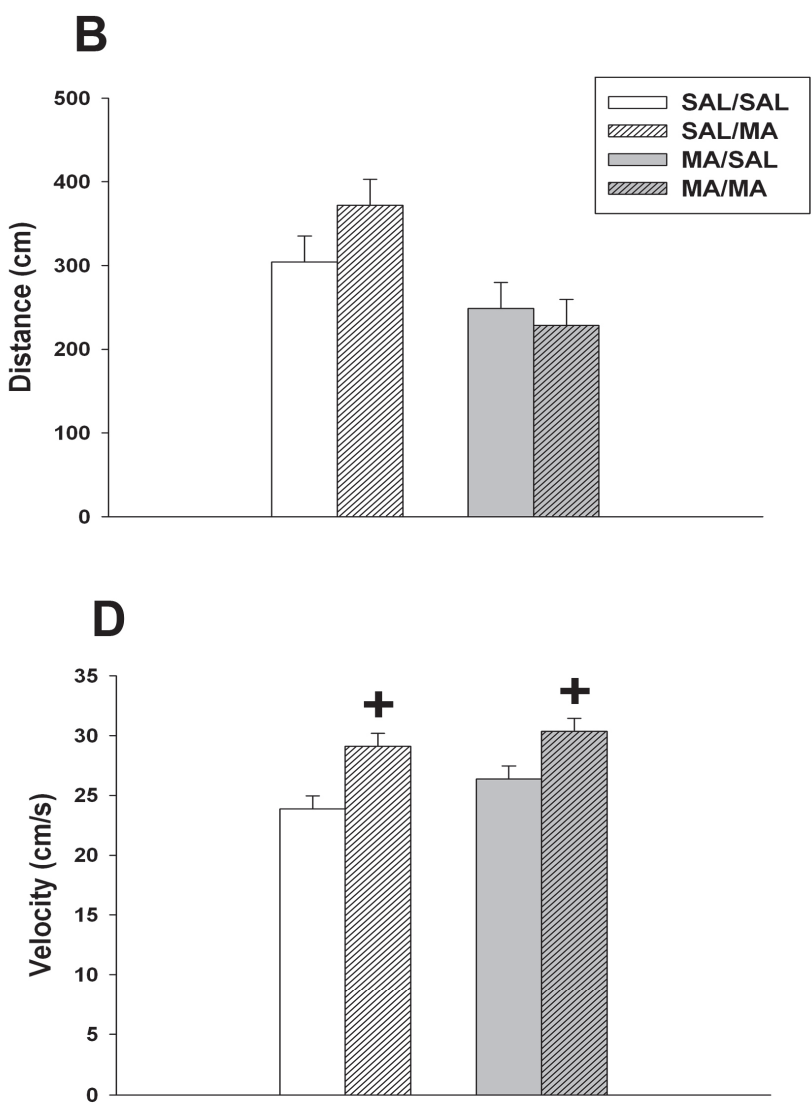

Fig. 2. Memory after chronic MA treatment in adulthood. The effect of prenatal MA exposure and long-term MA treatment in adulthood on performance in the MRT examined in the Morris Water Maze. Figures show: Latency of platform acquisition (A); Distance traveled (B); Search error (C); Velocity of swimming (D). Values are mean \pm SEM $(n=12) . * p<0.05$ = main effect of Prenatal exposure; prenatal saline $>$ prenatal MA, $+p<0.001=$ main effect of Adult treatment; Adult MA $>$ Adult SAL

\section{Results}

Evaluation of memory after acute MA treatment in adulthood

In the ORT (Fig. 1A), prenatally MA-exposed rats, regardless of the drug treatment in adulthood, displayed lower IR $[\mathrm{F}(1,40)=5.26 ; \mathrm{p}<0.05]$ than prenatally SAL-exposed rats. In the OLT (Fig. 1B), there was a main effect of Adult treatment $[\mathrm{F}(1,40)=7.37$; $\mathrm{p}<0.01]$ and an interaction between Prenatal exposure and Adult treatment $[\mathrm{F}(1,40)=6.54 ; \mathrm{p}<0.05]$. Specifically the results showed that prenatally MA-exposed rats treated with MA in adulthood (MA/MA) had lower IR in the OLT than prenatally MA-exposed rats treated in adulthood with SAL (MA/SAL) $(\mathrm{p}<0.01)$.

Evaluation of memory after long-term MA treatment in adulthood

\section{Morris Water Maze}

As shown in our previous study (Schutová et al. 2009), there were no effects of the Prenatal exposure and 
Adult treatment on the learning abilities: all animals were able to learn to find the platform efficiently.

In the MRT, animals prenatally exposed to MA (MA/SAL, MA/MA) had shorter latencies $[\mathrm{F}(1,44)=$ $6.22, \mathrm{p}<0.05]$ and search errors $[F(1,44)=6.21, \mathrm{p}<0.05]$ than animals prenatally exposed to SAL (SAL/SAL,
SAL/MA) (Fig. 2A, B). In addition, prenatally MAexposed rats swam less in the incorrect quadrants and searched the pool by using direct swim more than prenatally SAL-exposed rats $[\chi 2=24.14 ; \quad \mathrm{p}<0.001]$, regardless of Adult treatment (Table 1).

Table 1. The effect of Prenatal MA exposure and Adult challenge on the strategies used in the MWM.

\begin{tabular}{lcccc}
\hline Strategies & SAL / no MA & SAL / Adult MA & MA / no MA & MA / Adult MA \\
\hline Thigmotaxis & 2.1 & 0 & 0 & 0 \\
Random & 7.3 & 9.5 & 4.2 & 6.3 \\
Scanning & 0 & 0 & 0 & 0 \\
Chaining & 1.0 & 3.1 & 1.0 & 2.1 \\
Incorrect quadrant & 36.5 & $\mathbf{4 5 . 8 ^ { + }}$ & $\mathbf{2 9 . 2}^{*}$ & $\mathbf{2 7 . 0}^{*}$ \\
Search & 3.1 & 9.3 & 10.4 & 6.3 \\
Correct quadrant search & 50.0 & $\mathbf{3 2 . 3}^{+}$ & $\mathbf{5 5 . 2}^{*}$ & $\mathbf{5 8 . 3}^{*}$ \\
Direct swim & &
\end{tabular}

Values are percentages, $n=12, * p<0.001$ vs. prenatal $S A L,+p<0.001$ vs. SAL/no MA.
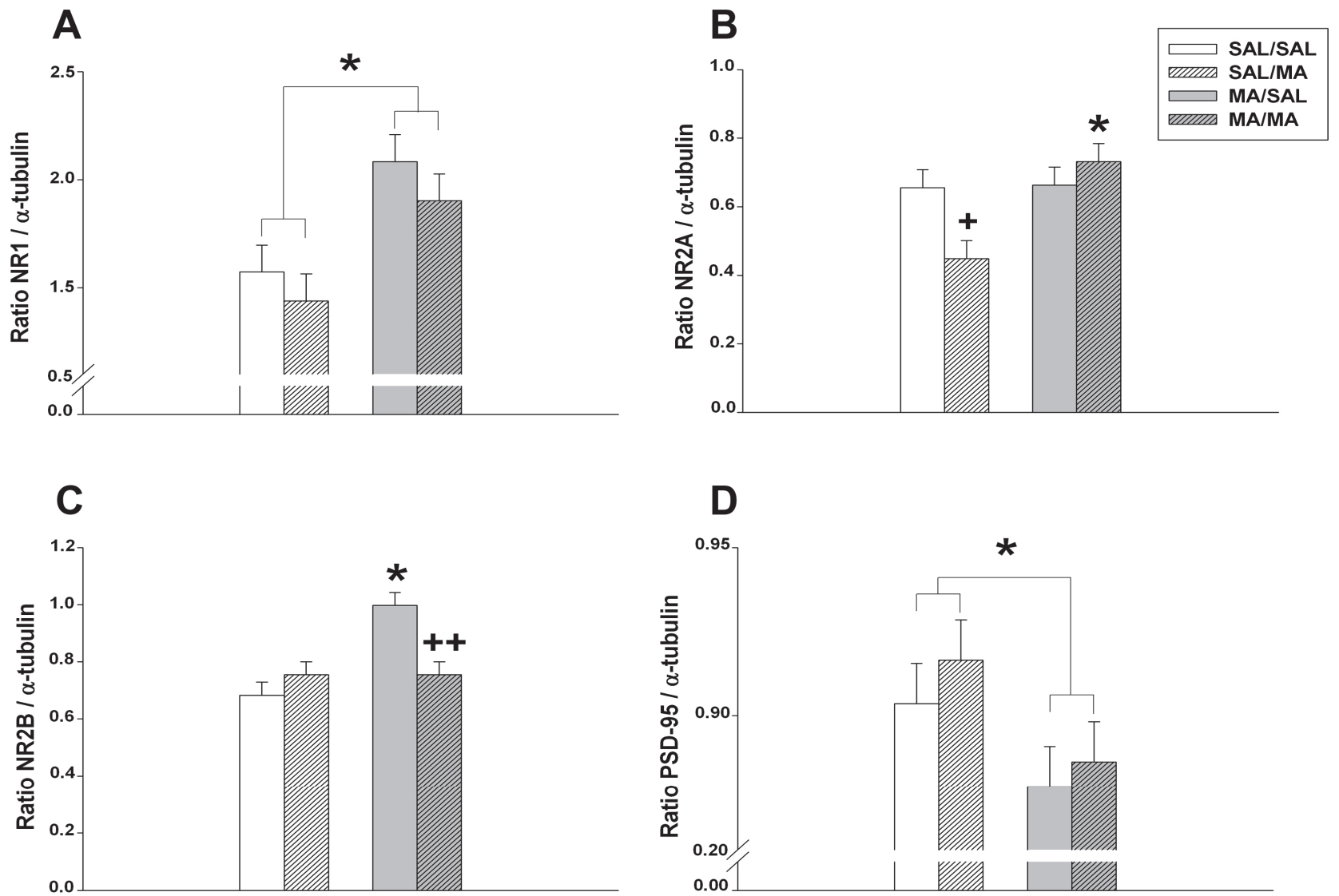

Fig. 3. Western blotting. The effect of prenatal MA exposure and long-term MA treatment in adulthood on expression of the NMDA receptor subunits in the hippocampus: NR1 (A); NR2A (B); NR2B (C); PSD-95 protein (D). Values are mean \pm SEM ( $n=12$ ). (A) $* \mathrm{p}<0.001=$ main effect of Prenatal exposure; prenatal saline $<$ prenatal MA, (B) $* p<0.001=\mathrm{MA} / \mathrm{MA}>\mathrm{SAL} / \mathrm{MA} ;+\mathrm{p}<0.01$ $\mathrm{SAL} / \mathrm{MA}<\mathrm{SAL} / \mathrm{SAL},(\mathbf{C}) * \mathrm{p}<0.001=\mathrm{MA} / \mathrm{SAL}>\mathrm{SAL} / \mathrm{SAL} ;++\mathrm{p}<0.001 \mathrm{MA} / \mathrm{MA}<\mathrm{MA} / \mathrm{SAL},(\mathbf{D}) * \mathrm{p}<0.001=$ main effect of Prenatal exposure; prenatal saline $>$ prenatal MA 
In contrast, no effects of Adult treatment was found for any of the spatial search measures \{latency $[F(1,44)=0.17, p=0.68]$, distance traveled $[F(1,44)=0.21$, $\mathrm{p}=0.65]$, search error $[\mathrm{F}(1,44)=0.32, \mathrm{p}=0.58]\}$ (Fig. 2A, $\mathrm{B}, \mathrm{C})$. However, Chi-square analysis of the frequency of search strategies revealed significant differences between groups of rats prenatally exposed to SAL, so that SAL group administered $\mathrm{MA}$ in adulthood (SAL/MA) searched the platform more in the incorrect quadrants of the MWM and swam directly to the platform less than $\mathrm{SAL}$ rats administered SAL in adulthood (SAL/SAL), $[\chi 2=26.91 ; \mathrm{p}<0.001]$ (Table 1$)$.

Further, significant main effect of Adult treatment for the velocity of swimming was demonstrated $[F(1,44)=18.01, \quad p<0.001], \quad$ such that all animals administered MA in adulthood, regardless of prenatal exposure, swam faster than the animals without MA application (Fig. 2D).

\section{Western Blotting}

\section{NR1 subunit protein}

Western Blot analyses of the hippocampi showed a significant main effect of Prenatal exposure $[F(1,28)=15.26, p<0.001]$ for semi-quantification of the NR1 subunit protein, expressed as a protein ratio of NR1 and $\alpha$-tubulin as a loading control, so that rats prenatally exposed to MA had increased NR1 expression in the hippocampi relative to SAL exposed rats (Fig. 3A).

\section{NR2A subunit protein}

For the expression of NR2A subunit in the hippocampus (calculated as a ratio of NR2A / $\alpha$-tubulin) a main effect of Prenatal exposure $[\mathrm{F}(1,28)=7.54$, $\mathrm{p}<0.05]$ as well as an interaction between Prenatal exposure and Adult treatment $[\mathrm{F}(1,28)=6.28, \mathrm{p}<0.05]$ were found. Post-hoc tests showed a significant decrease of NR2A expression in SAL/MA group relative to SAL/SAL and MA/MA groups $(\mathrm{p}<0.01$ and $\mathrm{p}<0.001$, respectively) (Fig. 3B).

\section{NR2B subunit protein}

A main effect of Prenatal exposure [F(1, 28) $=12.00, \mathrm{p}<0.01]$ and an interaction between Prenatal exposure and Adult treatment $[\mathrm{F}(1,28)=11.80, \mathrm{p}<0.01]$ were found also for NR2B subunit (calculated as a ratio of NR2B / $\alpha$-tubulin). Post-hoc test showed that NR2B subunit was increased in $\mathrm{MA} / \mathrm{SAL}$ group relative to SAL/SAL and MA/MA groups $(p<0.001)$ (Fig. 3C).

PSD-95

Expression of PSD-95 protein in the hippocampus calculated as a ratio of PSD-95 and $\alpha$-tubulin was decreased by prenatal MA exposure as a significant main effect of Prenatal exposure $[\mathrm{F}(1,28)=$ 5.29, $\mathrm{p}<0.05$ ] was shown (Fig. 3D).

\section{NR2 receptor subunit occurrence}

When compared the occurrence of NR2A and NR2B receptor in the experimental groups, the data (see Fig. 4) showed significant difference in animals prenatally exposed to SAL and treated in adulthood with MA (SAL/MA) and in prenatally MA-exposed animals treated in adulthood with SAL (MA/SAL) $[\mathrm{F}(1,56)=$ $17.95 ; \mathrm{p}<0.0001]$.

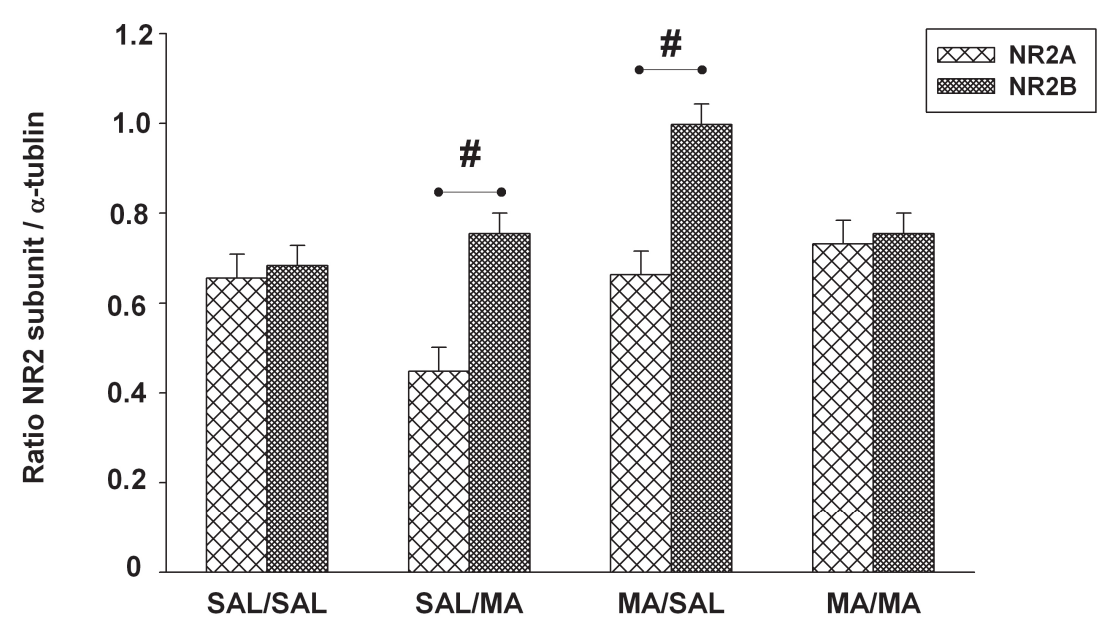

Fig. 4. Western blotting - comparison of NR2A and NR2B occurrence. The effect of prenatal MA exposure and long-term MA treatment in adulthood on the occurrence of two types of NR2 subunits. Values are mean $\pm \mathrm{SEM}$ $(n=12) . \# p<0.001=$ difference in the occurrence of NR2A and NR2B subunits 


\section{Discussion}

The goal of the present study was to determine changes in the expression of the NMDA receptor subunits after the long-term impact of prenatal MA exposure and the effect of MA exposure in adulthood, with respect of its influence on spatial and non-spatial memory in laboratory rats.

To examine the differences between the effect of MA treatment (prenatal or adult) on spatial memory and non-spatial memory the ORT and OLT were conducted. The present data demonstrate decrease of interest in the new object induced by prenatal MA exposure in the ORT and decrease of interest in the newly located familiar object that was apparent in prenatally MA-exposed rats treated in adulthood with MA (MA/MA) in the OLT. These results demonstrate poorer memory of old object or worse determination new from old object or their position by animals with MA treatment (prenatal or adult). Because ORT test was shown to examine declarative, non-spatial memory, while the OLT test rather spatial memory (Winters et al. 2008), our data suggest that prenatal MA exposure impairs non-spatial memory more than the spatial memory and that only MA/MA animals displayed impairment in the spatial memory. However note, that both of these test used only single acute MA injection $(1 \mathrm{mg} / \mathrm{kg})$ administered $30 \mathrm{~min}$ prior to testing in adulthood unlike in our MWM experiment in which long-term MA treatment in adulthood was used and in which totally different results were obtained (as discussed below).

When the spatial memory of adult male rats with long-term MA application $(1 \mathrm{mg} / \mathrm{kg})$ was tested in the MWM, the data showed that rats prenatally exposed to MA found the platform faster (had shorter latency) and had smaller search errors than rats prenatally exposed to SAL. Since both of these measures are used as measures of spatial orientation (Gallagher et al. 1993), prenatal MA exposure obviously improved spatial navigation in the MWM. This is further supported by the fact that rats prenatally exposed to MA used direct swim to find the platform more and swam in the incorrect quadrants less than rats prenatally exposed to SAL. These data are in agreement with our previous study (Schutová et al. 2009) showing similar effect of MA exposure in utero on memory. On the other hand, Acuff-Smith et al. (1996) demonstrated that prenatal MA exposure at the dose of 5 or $10 \mathrm{mg} / \mathrm{kg}$ did not affect memory in the MWM. However, they tested the memory on the other day after finishing the learning test, while in our study the MRT was done 7 days after the last acquisition trial. Thus, our results indicate that prenatal MA exposure of $5 \mathrm{mg} / \mathrm{kg}$ improved consolidation of the long-term memory in the MWM tested in adulthood.

In contrast, chronic MA administration was shown to induce memory impairments in drug abusers (Meredith et al. 2005). In the present study MA $(1 \mathrm{mg} / \mathrm{kg})$ or SAL were administered for eleven days before doing the MRT in adulthood. The data analysis revealed that MA administration in adulthood affected pattern of search strategies in prenatally SAL-exposed rats: rats from SAL/MA group used searching in the incorrect quadrants more and direct swim less than rats from all the other groups. However, this difference did not prevent SAL/MA rats from finding the platform as effectively as the other groups, since neither of the quantitative measures of spatial orientation (latency, distance, search error) differed between groups with and without MA administration in adulthood. Therefore, we cannot conclude that long-term MA administration in adulthood affected long-term memory in the MWM. The lack of memory impairment following MA in adulthood could be caused by the previous training in the acquisition trials despite the fact that MA was administered every day after finishing the trials. This hypothesis is supported by our previous study showing that MA in adulthood impaired learning in the MWM while it did not cause any changes in probe trial following the learning trials (Schutová et al. 2009). Furthermore, there are studies demonstrating that rats with hippocampal lesions can perform the MWM at the level of controls when they are over-trained (Whishaw and Tomie 1997). On the other hand, there are also studies demonstrating consistently with us that chronic MA administration did not induce changes in cognitive functions tested in Y maze or in object recognition task in adult animals (Belcher et al. 2008, Simoes et al. 2007).

As a matter of the expression of NMDA receptor subunits in the hippocampus, our results demonstrate that prenatal MA exposure, regardless of administration in adulthood increased NR1 expression levels, which is supported by studies showing that the abundance of NR1 correlates positively with performance in spatial memory tasks (Cammarota et al. 2000, Le Greves et al. 2006). Note that the NR1 subunit is an essential subunit for functional NMDA receptor (Lynch et al. 1994). As far as NR2 subunits are concerned, we found that their expression was affected differently by both prenatal 
exposure and application in adulthood. NR2A subunit levels were decreased by MA administered in adulthood only in rats prenatally exposed to SAL (SAL/MA), which might be associated with use of poor spatial strategies for searching the platform in the MWM relative to the other groups, since NMDA mediated LTP depends on the presence of NR2A (Grosshans et al. 2002). Although there are other studies showing that acute excitotoxic dose of MA increased NR2A subunit levels in the hippocampus (Grosshans et al. 2002, Simoes et al. 2007, 2008), in our study long-term administration of low MA dose $(1 \mathrm{mg} / \mathrm{kg})$ was used and therefore could have opposite effects to those of MA at high dosing regimen.

In contrast, NR2B subunit expression levels were not affected by MA challenge in adulthood in prenatally saline-exposed rats, which is in accordance with other study, where protein expression of NR2B in hippocampi of adult rats chronically treated with amphetamine, MA metabolite, was not changed (Mao et al. 2009). Likewise chronic cocaine treatment in adulthood did not cause significant changes in NR2B expression in rat hippocampus (Loftis and Janowsky 2003). Interestingly, NR2B subunit levels were increased by prenatal exposure to $\mathrm{MA}$ in rats that were administered SAL in adulthood, and this increase was suppressed with MA administration in adulthood. Thus, unlike NR2A, NR2B subunit expression was affected by prenatal exposure to MA, probably due to the fact that NR2B was shown to be abundant in immature brain playing an important role during development and synaptogenesis (McDonald and Johnston 1990). Further during development the NR2B is gradually replaced by the NR2A, expression of which therefore increases into adulthood (Haberny et al. 2002). In the present study, prenatal MA exposure seemed to delay the development of NMDA receptors resulting in change of NR2A/NR2B ratio. Overexpression of NR2B was shown to be associated with enhanced activation of NMDA receptors and facilitation of the LTP, corresponding with superior performance in various tests of learning and memory (Tang et al. 1999). Although it is only a speculation, increase in NR2B subunit levels could also contribute to better performance in MWM in rats prenatally exposed to MA.

In addition, rats prenatally exposed to MA, regardless of application in adulthood had decreased expression of PSD-95. Since MA was shown to increase extracellular glutamate in the hippocampus (Rocher and Gardier 2001), decrease in PSD-95 in the present study might work as a compensatory mechanism, protecting the developing brain against the over-activation of the NMDA receptors. This hypothesis is also supported by the fact that PSD-95 lacking neurons were shown to exhibit reduced neurotoxic vulnerability (Cui et al. 2007). On the other hand there are studies showing that PSD-95 acts as a negative regulator of LTP, with decreases in PSD-95 expression correlating with enhanced plasticity (Yao et al. 2004), which is in agreement with positive effect of prenatal MA exposure on memory in our study.

However, it should be noted that increase in NMDA activation and facilitation of memory formation need not necessarily result in positive consequences, only. Indeed, very close association was shown between drug addiction and memory formation, such that brain utilizes similar molecular and cellular mechanisms to form addiction-related memories as it does to form normal memories. Moreover, addiction-related memories develop faster and last longer than most other types of memories (Berke and Hyman 2000). Therefore, the increase of NR1 and NR2B subunits and decrease of PSD-95 by prenatal MA exposure could also promote the formation of addiction-related memories and thus, change the reactivity to drugs later in life.

The fact that we did not observe any changes in the locomotor response following long-term MA challenge between groups with different prenatal exposure was probably caused by the dosing regimen used - MA in adulthood was administered at least $24 \mathrm{~h}$ before performing the MRT. However, in other studies of ours, in which the same dose of MA was administered $30 \mathrm{~min}$ before behavioral testing, increased sensitivity of prenatally MA-exposed rats to acute dose of the same drug in adulthood was demonstrated (BubeníkováValešová et al. 2009, Schutová et al. 2010).

In conclusion, the present study demonstrates that prenatal MA exposure affects the development of NMDA receptors in the hippocampus that might correspond with improvement of long-term memory tested in adulthood. On the other hand, the effect of prenatal MA exposure on non-spatial memory is the opposite. It should be noted that non-spatial memory is not so closely associated with the hippocampus, but rather with the perirhinal or prefrontal cortex (Warburton and Brown 2010). Therefore, future studies will examine the structures of the NMDA receptors also in these brain areas. In addition, we show that the effect of MA administration in adulthood on NMDA receptors is influenced by prenatal MA exposure, which seems to 
correlate with the spatial memory examined in the OLT. To the best of our knowledge, there are not any other studies examining the effect of prenatal MA exposure on the long-term memory and NMDA receptors in adulthood, thus our study further extends the facts about the effects of MA abuse in pregnancy.

\section{Conflict of Interest}

There is no conflict of interest.

\section{Acknowledgements}

This study was supported by grant \# GA P303/10/0580 from Grant Agency of the Czech Republic, project \# NT/14484 from Internal Grant Agency of Ministry of Health of the Czech Republic, project \# PRVOUK P34, GAUK 545212 and project \# 260045/SVV/2014 from Charles University in Prague, \# CSM7/CRP/2014 from Ministry of Education, Youth and Sports of the Czech Republic.

\section{References}

ACUFF-SMITH KD, SCHILLING MA, FISHER JE, VORHEES CV: Stage-specific effects of prenatal dmethamphetamine exposure on behavioral and eye development in rats. Neurotoxicol Teratol 18: 199-215, 1996.

BELCHER AM, FEINSTEIN EM, O'DELL SJ, MARSHALL JF: Methamphetamine influences on recognition memory: comparison of escalating and single-day dosing regimens. Neuropsychopharmacology 33: 14531463, 2008.

BERKE JD, HYMAN SE: Addiction, dopamine, and the molecular mechanisms of memory. Neuron 25: 515-532, 2000.

BUBENÍKOVÁ-VALEŠOVÁ V, KAČER P, SYSLOVÁ K, RAMBOUSEK L, JANOVSKÝ M, SCHUTOVÁ B, HRUBÁ L, ŠLAMBEROVÁ R: Prenatal methamphetamine exposure affects the mesolimbic dopaminergic system and behavior in adult offspring. Int J Dev Neurosci 27: 525-530, 2009.

CAMMAROTA M, De STEIN ML, PARATCHA G, BEVILAQUA LR, IZQUIERDO I, MEDINA JH: Rapid and transient learning-associated increase in NMDA NR1 subunit in the rat hippocampus. Neurochem Res 25: 567$572,2000$.

CHANG L, SMITH LM, LOPRESTI C, YONEKURA ML, KUO J, WALOT I, ERNST T: Smaller subcortical volumes and cognitive deficits in children with prenatal methamphetamine exposure. Psychiatry Res 132: 95-106, 2004.

CHO DH, LYU HM, LEE HB, KIM PY, CHIN K: Behavioral teratogenicity of methamphetamine. $J$ Toxicol Sci $\mathbf{1 6}$ (Suppl 1): 37-49, 1991.

CONSTANTINE-PATON M, CLINE HT: LTP and activity-dependent synaptogenesis: the more alike they are, the more different they become. Curr Opin Neurobiol 8: 139-148, 1998.

CROZATIER C, GUERRIERO RM, MATHIEU F, GIROS B, NOSTEN-BERTRAND M, KOSOFSKY BE: Altered cocaine-induced behavioral sensitization in adult mice exposed to cocaine in utero. Brain Res Dev Brain Res 147: 97-105, 2003.

CUI H, HAYASHI A, SUN HS, BELMARES MP, COBEY C, PHAN T, SCHWEIZER J, SALTER MW, WANG YT, TASKER RA, GARMAN D, RABINOWITZ J, LU PS, TYMIANSKI M: PDZ protein interactions underlying NMDA receptor-mediated excitotoxicity and neuroprotection by PSD-95 inhibitors. J Neurosci 27: 9901-9915, 2007.

DATTEL BJ: Substance abuse in pregnancy. Semin Perinatol 14: 179-187, 1990.

DAVIS S, BUTCHER SP, MORRIS RG: The NMDA receptor antagonist D-2-amino-5-phosphonopentanoate (D-AP5) impairs spatial learning and LTP in vivo at intracerebral concentrations comparable to those that block LTP in vitro. J Neurosci 12: 21-34, 1992.

ENNACEUR A, NEAVE N, AGGLETON JP: Spontaneous object recognition and object location memory in rats: the effects of lesions in the cingulate cortices, the medial prefrontal cortex, the cingulum bundle and the fornix. Exp Brain Res 113: 509-519, 1997.

GALLAGHER M, BURWELL R, BURCHINAL M: Severity of spatial learning impairment in aging: development of a learning index for performance in the Morris water maze. Behav Neurosci 107: 618-626, 1993. 
GLATT SJ, BOLANOS CA, TRKSAK GH, CROWDER-DUPONT C, JACKSON D: Prenatal cocaine exposure alters behavioral and neurochemical sensitization to amphetamine in adult rats. Neuropharmacology 39: 599-610, 2000.

GRIFFITHS P, MRAVCIK V, LOPEZ D, KLEMPOVA D: Quite a lot of smoke but very limited fire - the use of methamphetamine in Europe. Drug Alcohol Rev 27: 236-242, 2008.

GROSSHANS DR, CLAYTON DA, COULTRAP SJ, BROWNING MD: LTP leads to rapid surface expression of NMDA but not AMPA receptors in adult rat CA1. Nat Neurosci 5: 27-33, 2002.

HABERNY KA, PAULE MG, SCALLET AC, SISTARE FD, LESTER DS, HANIG JP, SLIKKER W Jr: Ontogeny of the N-methyl-D-aspartate (NMDA) receptor system and susceptibility to neurotoxicity. Toxicol Sci 68: 9-17, 2002.

HANSON GR, RAU KS, FLECKENSTEIN AE: The methamphetamine experience: a NIDA partnership. Neuropharmacology 47 (Suppl 1): 92-100, 2004.

HRUBÁ L, SCHUTOVÁ B, ŠLAMBEROVÁ R, POMETLOVÁ M, ROKYTA R: Effect of methamphetamine exposure and cross-fostering on sensorimotor development of male and female rat pups. Dev Psychobiol 51: 73-83, 2009.

ISHII T, MORIYOSHI K, SUGIHARA $\mathrm{H}$, SAKURADA K, KADOTANI $\mathrm{H}$, YOKOI M, AKAZAWA C, SHIGEMOTO R, MIZUNO N, MASU M ET AL.: Molecular characterization of the family of the N-methylD-aspartate receptor subunits. J Biol Chem 268: 2836-2843, 1993.

JANUS C: Search strategies used by APP transgenic mice during navigation in the Morris water maze. Learn Mem 11: 337-346, 2004.

LAURIE DJ, BARTKE I, SCHOEPFER R, NAUJOKS K, SEEBURG PH: Regional, developmental and interspecies expression of the four NMDAR2 subunits, examined using monoclonal antibodies. Brain Res Mol Brain Res 51: 23-32, 1997.

LE GREVES M, ZHOU Q, BERG M, LE GREVES P, FHOLENHAG K, MEYERSON B, NYBERG F: Growth hormone replacement in hypophysectomized rats affects spatial performance and hippocampal levels of NMDA receptor subunit and PSD-95 gene transcript levels. Exp Brain Res 173: 267-273, 2006.

LOFTIS JM, JANOWSKY A: The N-methyl-D-aspartate receptor subunit NR2B: localization, functional properties, regulation, and clinical implications. Pharmacol Ther 97: 55-85, 2003.

LYNCH DR, ANEGAWA NJ, VERDOORN T, PRITCHETT DB: N-methyl-D-aspartate receptors: different subunit requirements for binding of glutamate antagonists, glycine antagonists, and channel-blocking agents. Mol Pharmacol 45: 540-545, 1994.

MAO LM, WANG W, CHU XP, ZHANG GC, LIU XY, YANG YJ, HAINES M, PAPASIAN CJ, FIBUCH EE, BUCH S, CHEN JG, WANG JQ: Stability of surface NMDA receptors controls synaptic and behavioral adaptations to amphetamine. Nat Neurosci 12: 602-610, 2009.

MARTIN JC, MARTIN DC, RADOW B, SIGMAN G: Growth, development and activity in rat offspring following maternal drug exposure. Exp Aging Res 2: 235-251, 1976.

MCDONALD JW, JOHNSTON MV: Physiological and pathophysiological roles of excitatory amino acids during central nervous system development. Brain Res Rev 15: 41-70, 1990.

MEREDITH CW, JAFFE C, ANG-LEE K, SAXON AJ: Implications of chronic methamphetamine use: a literature review. Harv Rev Psychiatry 13: 141-154, 2005.

NORDAHL TE, SALO R, LEAMON M: Neuropsychological effects of chronic methamphetamine use on neurotransmitters and cognition: a review. J Neuropsychiatry Clin Neurosci 15: 317-325, 2003.

O'KEEFE J: Do hippocampal pyramidal cells signal non-spatial as well as spatial information? Hippocampus 9: 352364, 1999.

ROCHER C, GARDIER AM: Effects of repeated systemic administration of d-Fenfluramine on serotonin and glutamate release in rat ventral hippocampus: comparison with methamphetamine using in vivo microdialysis. Naunyn Schmiedebergs Arch Pharmacol 363: 422-428, 2001.

SCHNELL E, SIZEMORE M, KARIMZADEGAN S, CHEN L, BREDT DS, NICOLL RA: Direct interactions between PSD-95 and stargazin control synaptic AMPA receptor number. Proc Natl Acad Sci USA 99: 13902-13907, 2002. 
SCHUTOVÁ B, HRUBÁ L, POMETLOVÁ M, DEYKUN K, ŠLAMBEROVÁ R: Cognitive functions and drug sensitivity in adult male rats prenatally exposed to methamphetamine. Physiol Res 58: 741-750, 2009.

SCHUTOVÁ B, HRUBÁ L, POMETLOVÁ $M$, ROKYTA $R$, ŠLAMBEROVÁ R: Responsiveness to methamphetamine in adulthood is altered by prenatal exposure in rats. Physiol Behav 99: 381-387, 2010.

SCHUTOVÁ B, HRUBÁ L, ROKYTA R, ŠLAMBEROVÁ R: Gender differences in behavioral changes elicited by prenatal methamphetamine exposure and application of the same drug in adulthood. Dev Psychobiol 55: 232$242,2013$.

SHENG M: The postsynaptic NMDA-receptor-PSD-95 signaling complex in excitatory synapses of the brain. $J$ Cell Sci 114: 1251, 2001.

SIMOES PF, SILVA AP, PEREIRA FC, MARQUES E, GRADE S, MILHAZES N, BORGES F, RIBEIRO CF, MACEDO TR: Methamphetamine induces alterations on hippocampal NMDA and AMPA receptor subunit levels and impairs spatial working memory. Neuroscience 150: 433-441, 2007.

SIMOES PF, SILVA AP, PEREIRA FC, MARQUES E, MILHAZES N, BORGES F, RIBEIRO CF, MACEDO TR: Methamphetamine changes NMDA and AMPA glutamate receptor subunit levels in the rat striatum and frontal cortex. Ann N Y Acad Sci 1139: 232-241, 2008.

STRUTHERS JM, HANSEN RL: Visual recognition memory in drug-exposed infants. J Dev Behav Pediatr 13: 108$111,1992$.

ŠLAMBEROVÁ R, CHAROUSOVÁ P, POMETLOVÁ M: Methamphetamine administration during gestation impairs maternal behavior. Dev Psychobiol 46: 57-65, 2005.

ŠLAMBEROVÁ R, MIKULECKÁ A, POMETLOVÁ M, SCHUTOVÁ B, HRUBÁ L, DEYKUN K: Sex differences in social interaction of methamphetamine-treated rats. Behav Pharmacol 22: 617-623, 2011.

TANG Q, GANDHOKE R, BURRITT A, HRUBY VJ, PORRECA F, LAI J: High-affinity interaction of (desTyrosyl)dynorphin A(2-17) with NMDA receptors. J Pharmacol Exp Ther 291: 760-765, 1999.

WARBURTON EC, BROWN MW: Findings from animals concerning when interactions between perirhinal cortex, hippocampus and medial prefrontal cortex are necessary for recognition memory. Neuropsychologia 48: 22622272, 2010.

WHISHAW IQ, TOMIE J: Perseveration on place reversals in spatial swimming pool tasks: further evidence for place learning in hippocampal rats. Hippocampus 7: 361-370, 1997.

WINTERS BD, SAKSIDA LM, BUSSEY TJ: Object recognition memory: neurobiological mechanisms of encoding, consolidation and retrieval. Neurosci Biobehav Rev 32: 1055-1070, 2008.

YAO WD, GAINETDINOV RR, ARBUCKLE MI, SOTNIKOVA TD, CYR M, BEAULIEU JM, TORRES GE, GRANT SG, CARON MG: Identification of PSD-95 as a regulator of dopamine-mediated synaptic and behavioral plasticity. Neuron 41: 625-638, 2004. 